\title{
Predicting Sources of Dissolved Organic Nitrogen to an Estuary from an Agro-Urban Coastal Watershed
}

\section{Supporting Information}

Osburn, Christopher L..$^{*}$, Handsel, Lauren T. ${ }^{1 \#}$, Peierls, Benjamin L. ${ }^{2}$, and Paerl, Hans W. ${ }^{2}$

${ }^{1}$ Department of Marine, Earth, and Atmospheric Science, North Carolina State University, Raleigh, North Carolina, 27695 USA

${ }^{2}$ Institute of Marine Sciences, University of North Carolina at Chapel Hill, Morehead City, North Carolina, USA

*corresponding author, +1-919-515-0382; closburn@ncsu.edu

\#now at Cardno, Inc., Raleigh, NC

Prepared for: Environmental Science and Technology

These 17 pages contain 8 tables and 2 figures, as described in the Table of Contents. 


\section{Table of Contents}

Nitrogen loading and regulation in the Neuse River Basin and Estuary......................S3

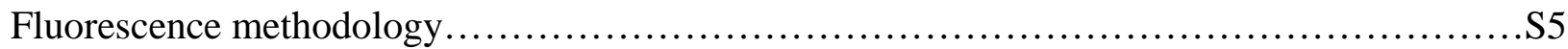

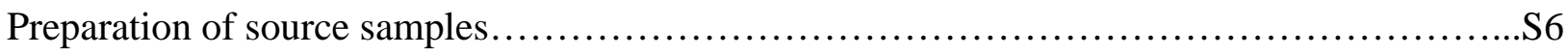

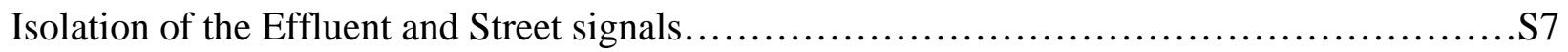

Split-Half Validation Results for the PARAFAC model $. . \ldots \ldots \ldots \ldots \ldots \ldots \ldots \ldots \ldots \ldots \ldots \ldots \ldots . . .58$

Approach to creating the PARAFAC model of sources.................................. 9

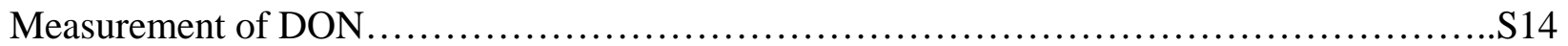

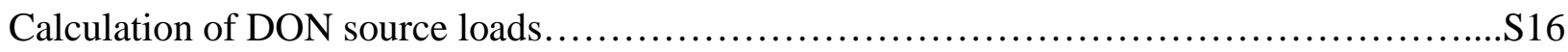

References.................................................................... 17 


\section{Appendix 1. Nitrogen loading and regulation in the Neuse River Basin and Estuary}

Over the past several decades, the NRE has undergone nutrient-driven eutrophication and suffered from a range of disruptive symptoms including algal blooms, hypoxia, and fish kills ${ }^{1-3}$. These conditions led the then-North Carolina Department of Environment and Natural Resources-Division of Water Quality (NCDENR-DWQ) to add the NRE to the Environmental Protection Agency’s 303(d) list of impaired waters in 1994 and later to implement a Total Maximum Daily Load (TMDL), prescribing a 30\% reduction in total N (TN) loading ${ }^{4}$.

The required 30\% reduction in TN delivered to the NRE from its river basin (the NRB) has not been achieved and portions of the NRE remain impaired based on samples exceeding the state's criterion of $40 \mu g \mathrm{~L}^{-1}$ chlorophyll a (Chl-a) ${ }^{4}$. Recent trend analysis shows that despite decreases in nitrate-N loading from the NRB, total Kjeldahl $\mathrm{N}$ (TKN = organic $\mathrm{N}$ plus ammonium) loading has increased, resulting in little change for total $\mathrm{N}$ loading to the estuary ${ }^{4,5}$. That, combined with the lack of a trend for ammonia/ammonium-N, suggests that the increase is due to the organic forms of $\mathrm{N}$, either dissolved, particulate, or both.

The Lower Neuse Basin Association (LNBA) operates a monthly sampling plan that we utilized to collect surface water samples on which FluorMod was tested ${ }^{6}$. Locations (Lat $=$ latitude, Lon = Longitude; in decimal degrees) and land cover classifications for select locations in the NRB that were the focus of this study are presented in Table S1. Developed cover was the sum of developed open space, low-, medium-, and high-intensities, and barren land. Forest cover was the sum of deciduous forest, evergreen forest, mixed forest, shrub/scrub, and herbaceous classifications. Cropland cover was the sum of cultivated crops and hay and pasture. Wetlands cover was the sum of woody wetland and emergent herbaceous wetlands. 
Table S1. Location and land use and land cover percentages along the main stem and tributaries of the Neuse River Basin. Note: Cropland includes cropland and hay/pasture.

\begin{tabular}{lllllll}
\hline Station & Lat & Lon & Developed & Forest & Cropland & Wetlands \\
\hline Main stem & & & & & & \\
Raleigh & 35.7266 & -78.5139 & 27.35 & 54.14 & 13.88 & 2.19 \\
Clayton & 35.6473 & -78.4056 & 26.63 & 54.38 & 14.36 & 2.28 \\
Kinston & 35.2588 & -77.5835 & 19.72 & 42.31 & 26.11 & 10.15 \\
Fort & 35.3139 & -77.3030 & 16.38 & 37.69 & 31.26 & 13.14 \\
Barnwell & & & & & & \\
Tributaries & & & & & & \\
Crabtree & 35.8212 & -78.6341 & & & & \\
Creek & & & 65.42 & 29.22 & 2.69 & 1.08 \\
Middle & 35.5075 & -78.4013 & & & & \\
Creek & & & 27.12 & 43.34 & 20.27 & 8.51 \\
Little River & 35.8125 & -78.2681 & 15.18 & 48.00 & 29.13 & 14.01 \\
Bear Creek & 35.2489 & -77.7843 & 8.78 & 21.19 & 55.23 & 16.97 \\
Contentnea & 35.4286 & -77.5827 & 27.12 & 28.54 & 43.36 & \\
Creek & & & & & & \\
Trent River & 35.06364 & -77.46107 & 3.84 & 38.91 & 25.14 & \\
\hline
\end{tabular}




\section{Appendix 2. Fluorescence methodology}

Depending on the sample, lamp settings of 700 to 950 volts to achieve a detector response of roughly 800 (arbitrary units; 1000 maximum) at $250 \mathrm{~nm}$ excitation. Raw fluorescence was corrected for lamp excitation and emission detector response using manufacturer supplied corrections. Next, inner filtering effects were corrected using the aforementioned absorption coefficients. Thus matching dilutions was important and carefully conducted on all samples. Finally, a MilliQ water scan was corrected for lamp excitation and emission detector and was subtracted from the sample. Any negative values were set equal to zero and then the fluorescence intensity was calibrated to the water Raman signal of the instrument and finally converted to quinine sulfate units. Final values were calibrated in quinine sulfate units (QSU, where $1 \mathrm{QSU}=1 \mathrm{ppb}$ quinine sulfate). Details of these processing steps can be found in Murphy et al. ${ }^{7}$. Three dimensional fluorescence $(\mathrm{Ex} \times \mathrm{Em} \times$ intensity) are arranged as excitation-emission matrices (EEMs) and viewed as contour plots representing fluorescence landscapes ${ }^{8}$. 


\section{Appendix 3. Preparation of Source Samples}

Two 'Reference’ streams (Deep Creek and Little River) represented the natural background source of $\mathrm{ON}$ in a stream not receiving discharges from wastewater treatment facilities (WWTF), street or storm water runoff over paved surfaces, and not having poultry or swine operations in their watersheds ${ }^{9}$. Reference streams were classified as Outstanding Resource Water (ORW) ${ }^{4}$. Despite these streams being classified as ORWs, we cannot discount inputs of ON from migrating waterfowl or the atmosphere, though we expect those to be small relative to inputs from plants (especially stems and leaves) and soils in each stream's watershed. Moreover, we cannot rule out the influence of septic systems in either stream's watershed, though each has low surrounding development. 'Influent' and 'Effluent' samples were contributed from WWTF within the Neuse River Basin. 'Swine' and 'Poultry' samples from the North Carolina Department of Agriculture (NCDA) laboratory were blind samples as we did not know their location only that they came from farms in the Neuse River Basin.

Collection of 'Street' runoff samples was made roadside near storm drains. 'Septic' were samples collected from residential community septic discharge ditches around the City of Durham, NC. Note these samples were not discretely in the NRB, but representative of sewerage effluents draining into streams in urban areas of NC. 'Soil' samples were leachates made similar to Poultry leachates. 


\section{Appendix 4. Isolation of the Effluent and Street signals.}

Mixture of sources presented a challenge for our forward based modeling approach. Because PARAFAC is a an additive model, we reasoned that subtraction could be used to isolate signals such as Effluent which contains Reference DOM as well as Effluent DOM (Fig. 1). Examples of the new Effluent and Street source signals are shown in Figure S3 and can be compared to Figures 1a, 1b, and $1 \mathrm{~h}$ in the main text. The residuals were rescaled, and this subtraction procedure meant that the spectral shapes of the fluorescence rather than fluorescence intensity comprised these new signals. While this step may have caused problems in the PARAFAC analysis on unscaled fluorescence, ultimately this did not matter because the intensities of the sources were again normalized prior to fitting the PARAFAC model ${ }^{7}$.
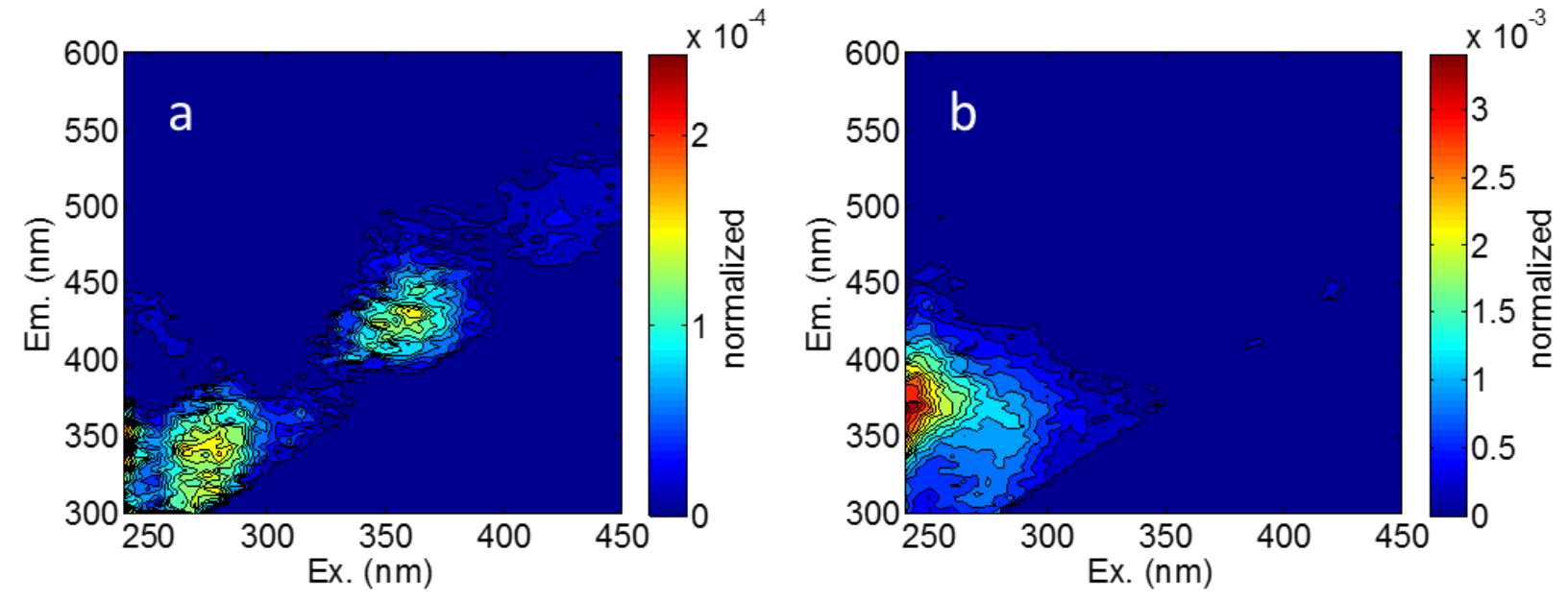

Figure S1. Results of the subtraction of the mean of Reference EEMs from (a) Effluent and (b) Street EEMs to create specific fluorescence source signals. Negative values were zeroed prior to these corrected EEMs being used as discrete sources in FluorMod. 


\section{Appendix 5. Split-Half Validation Results for the PARAFAC model.}
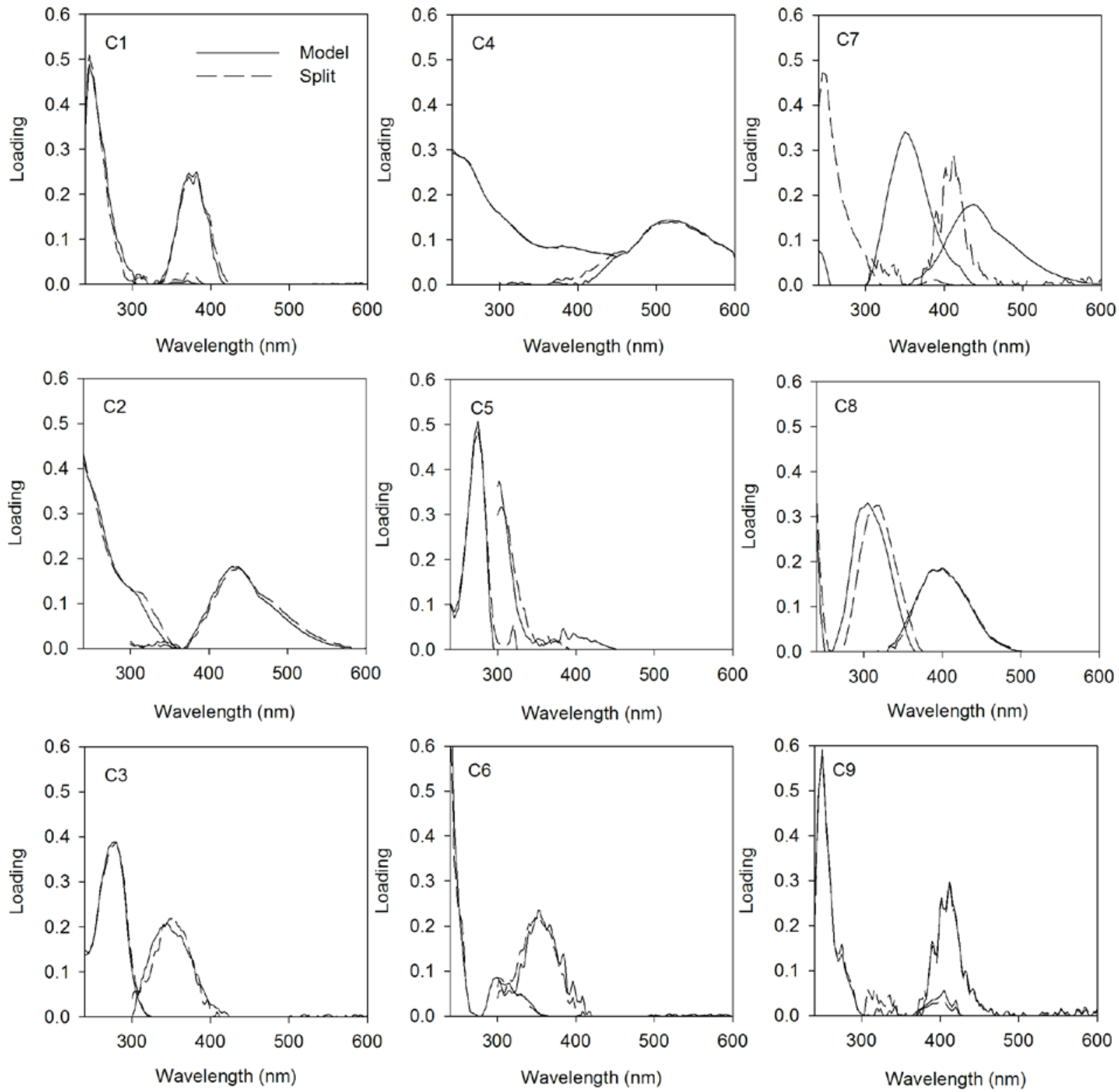

Figure S2. Results of split-half validation test for 9 component PARAFAC model used to build FluorMod. 


\section{Appendix 6: Approach to creating the PARAFAC model of sources}

FluorMod is a forward model; EEM fluorescence was measured on discrete sources as described in the text and in Appendices 3 and 4 and combined in an array that was modeled with PARAFAC. That PARAFAC model that was then fit to EEM fluorescence measured on stream samples from the Neuse River Basin. A mixing model on the 9 components applied to the stream and river samples was used to determine the relative amount of each of the eight DON sources. This appendix describes in greater detail how we approached creating FluorMod based on a PARAFAC model of probable sources of DON to streams in the NRB.

First, PARAFAC models are most stable when the modeled EEMs represent roughly equal amounts of variation ${ }^{7}$. For example, in a data set of 60 EEMs, if 4 EEMs have unique features compared to others, they may exert large leverage on the model and could be removed as outliers. In our forward modeling approach we faced this problem because we had unequal numbers of EEMs from each source (Table S2). Therefore, we used a Monte Carlo approach to randomly resample under-represented source categories Reference, Street, and Soil, with resamples created from a normal distribution of each source ${ }^{10}$. We classified each EEM a priori as representative of a specific source and created a model from multiple sources - not from multiple stream samples. The latter represents a reverse modeling approach in which the source signals are extracted, and is the means by which most PARAFAC models are determined for dissolved organic matter. The forward modeling approach is different in that we created a model of sources of DON that we determined would potentially be present in Neuse River Basin stream and river waters. We used that rationale to generate replicates needed to stabilize the PARAFAC model, meaning that all sources having leverages $<0.25$ were included in the model. We resampled to bring to 24 the total number of EEMs from each of the eight sources of DON used 
for this study. However, for some source categories, <24, but at least 20, EEMs were included in the final model (Table S2), based on leverages. For FluorMod, we tested PARAFAC models having 4-13 components. Using split half validation we determined a final 9-component PARAFAC model which we further validated by re-fitting the model 10 times with random starting points (Random Initialization procedure ${ }^{11}$ ).

Source categories Effluent, Influent, Poultry, Septic, and Swine consisted of at least 20 discrete EEMs and were not resampled prior to fitting the PARAFAC model. However, Reference, Soil, and Street sources each had <20 EEMs (Table S2). Reference sources consisted of 2 samplings each of Deep Creek and Little River, which were the only two streams deemed ORW (see Appendix 3). We resampled Reference, Street, and Soil source EEMs as described in

Table S2. Number of each of 8 source samples used to create FluorMod. N (original) is the number of original EEMs for each source; '\# revisits' is the number of times a source site was revisited and a sample taken; and $\mathrm{N}$ (resample) is the number of random EEMs taken from the multivariate normal distribution of each source required to bring the total $\mathrm{N}$ for each source to 24. $\mathrm{N}$ (removed) is the number of EEMs removed from the final PARAFAC model due to leverages $>0.25$. $\mathrm{N}$ (final) is the final number of EEMs from each category in the 9-component PARAFAC model. *Revisits for Deep Creek and Little River.

\begin{tabular}{cccccc}
\hline Source category & N (original) & $\begin{array}{c}\# \\
\text { revisits }\end{array}$ & $\begin{array}{c}\mathbf{N} \\
\text { (resample) }\end{array}$ & $\begin{array}{c}\mathbf{N} \\
\text { (removed) }\end{array}$ & $\begin{array}{c}\mathbf{N} \\
\text { (final) }\end{array}$ \\
\hline Reference & 4 & $2^{*}$ & 20 & 0 & 24 \\
Effluent & 24 & 0 & 0 & 0 & 24 \\
Influent & 24 & 0 & 0 & 0 & 24 \\
Poultry & 24 & 0 & 0 & 0 & 24 \\
Septic & 24 & 0 & 0 & 3 & 21 \\
Soil & 12 & 0 & 12 & 1 & 23 \\
Street & 20 & $1-9$ & 4 & 3 & 21 \\
Swine & 24 & 0 & 0 & 4 & 20 \\
\hline
\end{tabular}

Table S2.

The Reference source contained the least number of observations. Using a Durbin- 
Watson test, no autocorrelation was found for revisits made at Reference streams $(p=0.105)$. If the significance of the $\mathrm{D}-\mathrm{W}$ test was $<0.05$, the null hypothesis that linear regression residuals are uncorrelated is rejected. Resampling of the four Reference EEMs was done to generate 20 additional EEMs for the PARAFAC model.

The Street runoff source contained the most revisits for a particular site. Table S3 shows the sample collection scheme for each Street location, along with results of a Durbin-Watson test to evaluate autocorrelation, which was found for Pigeon House Branch but was based only on four samples. Therefore, we were satisfied that we had as little autocorrelation as possible given

Table S3. Locations where street runoff ('Street') samples were collected for this study. 'DW significance' is the significance of the Durbin-Watson statistic.

\begin{tabular}{ccccc}
\hline Street source site & Lat $\left({ }^{\circ} \mathbf{N}\right)$ & Lon $\left({ }^{\circ} \mathbf{W}\right)$ & \# revisits & $\begin{array}{c}\text { D-W } \\
\text { significance }\end{array}$ \\
\hline Marsh Creek & 35.816799 & -78.593047 & 6 & 0.93 \\
Pigeon House Creek & 35.787868 & -78.655033 & 4 & 0.04 \\
Rocky Branch & 35.781943 & -78.671116 & 9 & 0.09 \\
Morrill Drive & 35.781914 & -78.671548 & 1 & n.a. \\
irregular sampling of the same system ${ }^{12}$. & & &
\end{tabular}

Next, the hypothesis that fluorescence can be used to assess DON sources was tested by correlating DON concentration with PARAFAC components (Table S4). The data were not normally distributed so Spearman rank correlation was selected. Spearman’s rho ( $\rho$ ) values ranged from 0.34 for C6 to 0.76 for C8. All correlations were significant $(\mathrm{P}<0.001)$, indicating that each component could be used to model DON sources. 
Table S4. Results of Spearman rank correlation ( $\rho$ ) between DON concentration and each of the 9 PARAFAC component FMax values $(\mathrm{N}=311)$. $\mathrm{P}$ is the significance of the correlation.

\begin{tabular}{ccc}
\hline PARAFAC Component & $\boldsymbol{\rho}$ & $\mathbf{P}$ \\
\hline C1 & 0.556 & $1.152 \times 10^{-26}$ \\
C2 & 0.703 & $1.257 \times 10^{-47}$ \\
C3 & 0.592 & $8.199 \times 10^{-31}$ \\
C4 & 0.659 & $3.661 \times 10^{-40}$ \\
C5 & 0.505 & $1.590 \times 10^{-21}$ \\
C6 & 0.341 & $6.896 \times 10^{-10}$ \\
C7 & 0.758 & $2.349 \times 10^{-59}$ \\
C8 & 0.763 & $1.999 \times 10^{-60}$ \\
C9 & 0.480 & $2.314 \times 10^{-19}$
\end{tabular}

Last, the PARAFAC model was applied to each stream or river sample and then a

Monte-Carlo based mixing model was used to estimate each percentage of the 8 total sources in a particular stream or river sample as described in the main text. A total of 516 stream and river samples were modeled from nine locations in the Neuse River Basin at and above Ft. Barnwell, NC. Trent River also was modeled but this tributary enters the Neuse River Estuary directly and not via the river upstream of Ft. Barnwell. The results of mixing model in terms of predicting source contributions (as a percentage of the total DON) are shown in Table S5. The grouped sources are tabulated in Table 3 of the main text.

Table S5. Percentages of DON in the Neuse River Basin tributaries and main-stem sites predicted by FluorMod from Aug 2011- May 2013. REF = Reference; EFF = Effluent; INF = Influent; PLT = Poultry; SWI = Swine; SEP = Septic; STR = Street runoff; Urban = urban sources (sum of EFF + INF + SEP + STR); Agriculture = animal waste sources (sum of PLT + SWI). Gray shaded values indicate model runs in which a particular source was excluded due to land use analysis. $\mathrm{N}$ is the number of stream or river observations modeled.

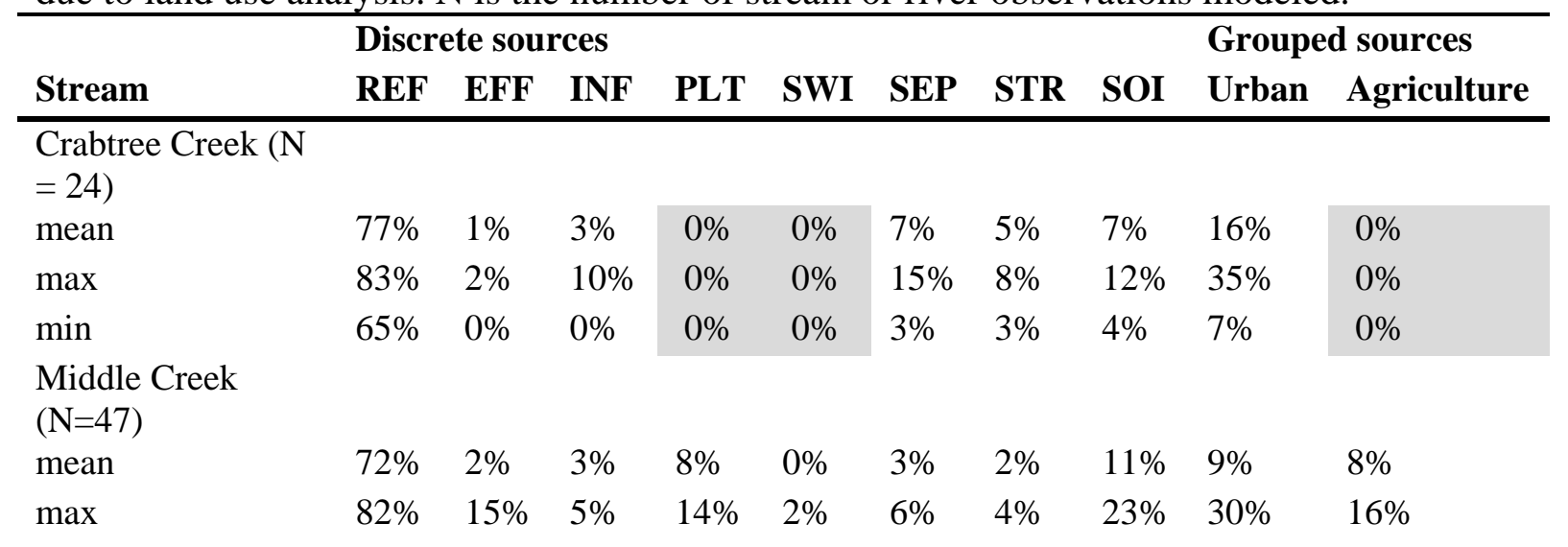




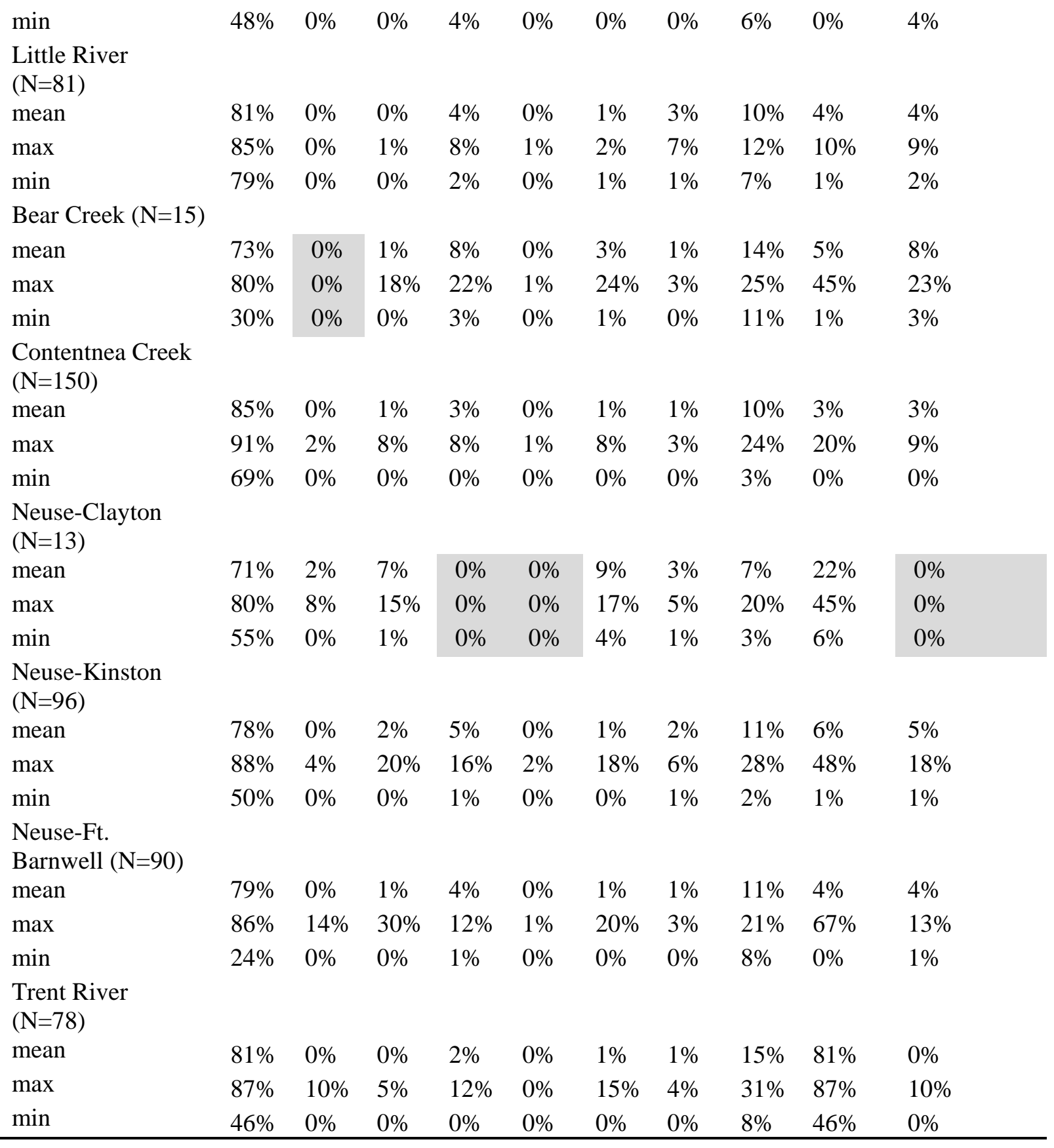




\section{Appendix 7. Measurement of DON}

For roughly $30 \%$ of the samples, DON was calculated as difference between DIN and TDN concentrations. For the rest, the sums of ammonium and PN concentrations were subtracted from TKN concentrations to give DON concentrations (per Standard Methods $4500-\mathrm{N}_{\text {org }}$ ). Replication on nitrogen analyses of 12 samples allowed us to report relative standard deviation (RSD) of our ammonium, nitrite/nitrate, TDN, DIN, and DON measurements. RSD is expressed as a percentage in Table S6.

Table S6. Relative standard deviations (RSD) of N assays and computed N concentrations on duplicate samples expressed as a percentage.

\begin{tabular}{llllll}
\hline & Ammonium & Nitrite/nitrate & TDN & DIN & DON \\
\hline RSD & $8 \%$ & $4.5 \%$ & $5.7 \%$ & 4.5 & $13 \%$
\end{tabular}

Use of the two methods arose from separate sampling programs and laboratories making these measurements which was unavoidable. We acknowledge uncertainty in reproducibility through these methods as has been discussed recently ${ }^{13}$. DIN:TDN ratios show considerable variability ranging from 0.05 (river) to 0.98 (Swine lagoon), with a mean of 0.62 and a median of 0.59. Mean and standard deviation of DIN:TDN for select source and stream samples are summarized in Table S7. These means are similar to the threshold ratio where larger errors may start to occur ${ }^{13,14}$. However resolution of these two methods for computing DON concentrations is beyond the scope of this report.

Table S7. Summary of DIN:TDN ratios for selected source and stream samples used in this study. Mean and standard deviation (std. dev.) are reported. $\mathrm{N}=$ number of samples per sample type. Method indicates the method used to estimate DON as described in the SI text.

\begin{tabular}{lcrrl}
\hline Sample & Mean & Std. dev. & N & Method \\
\hline Sources & & & & \\
Reference & 0.60 & 0.08 & 2 & TDN-DIN \\
Effluent & 0.77 & 0.17 & 13 & TDN-DIN \\
Influent & 0.73 & 0.10 & 5 & TDN-DIN \\
Poultry & 0.36 & 0.21 & 7 & TDN-DIN
\end{tabular}


Soil

Street

Swine

Streams

Bear Creek

Contentnea Creek

Neuse River Ft. Barnwell
0.71

0.64

0.94

0.78

0.50

0.51 $\begin{array}{lll}0.05 & 6 & \text { TDN-DIN }\end{array}$

0.1031 TDN-DIN

0.0419 TDN-DIN

$0.07 \quad 6$ TKN-NH4-PON

0.1039 TKN-NH4-PON

0.0943 TKN-NH4-PON 


\section{Appendix 8. Calculation of DON source loads.}

A web-based version of LOADEST was employed using daily mean discharge data for at least

12 dates over the course of the study ${ }^{15}$. The full results of each source category are shown in

Table S8. Grouped results (urban, agriculture) are tabulated in the main text (Table 3).

Table S8. DON yields (kg N/ha/yr) for select tributaries in the NRB as well as the yield at Ft. Barnwell. The Trent River at Trenton is listed last because it flows in to the Neuse River Estuary downstream of Ft. Barnwell. Also included is the total DON load from each watershed.

\begin{tabular}{cccccccccccccc}
\hline & & \multicolumn{1}{c}{ Discrete sources } & & \multicolumn{4}{c}{$\begin{array}{c}\text { Grouped } \\
\text { sources }\end{array}$} \\
& & & & & & & & & & & & Total \\
DON \\
Stream & REF & EFF & INF & PLT & SWI & SEP & STR & SOI & URB & AGR & N/yr) \\
\hline Crabtree & & & & & & & & & & & & & \\
Creek & 2.84 & 0.02 & 0.12 & 0 & 0 & 0.27 & 0.20 & 0.26 & 0.61 & 0.00 & 114321 \\
Bear Creek & 4.43 & 0 & 0.08 & 0.47 & 0.01 & 0.17 & 0.06 & 0.87 & 0.31 & 0.48 & 91330 \\
Contentnea & & & & & & & & & & & \\
Creek & 1.21 & 0.00 & 0.01 & 0.04 & 0.00 & 0.01 & 0.02 & 0.14 & 0.04 & 0.04 & 271083 \\
Ft. Barnwell & 1.17 & 0.00 & 0.01 & 0.06 & 0.00 & 0.02 & 0.02 & 0.17 & 0.06 & 0.06 & 1491665 \\
Trent River & 0.92 & 0.00 & 0.00 & 0.03 & 0.00 & 0.01 & 0.01 & 0.17 & 0.02 & 0.03 & 118760 \\
\hline
\end{tabular}




\section{References}

1. Paerl, H. W.; Pinckney, J. L.; Fear, J. M.; Peierls, B. L. Ecosystem responses to internal and watershed organic matter loading: consequences for hypoxia in the eutrophying Neuse River Estuary, North Carolina, USA. Mar. Ecol. Prog. Ser. 1998, 166: 17-25.

2. Paerl, H. W., Valdes-Weaver, L. M., Joyner, A. R., and Winkelmann, V. Phytoplankton indicators of ecological change in the eutrophying Pamlico Sound system, North Carolina. Ecol. Appl. 2007, 17: S88-S101.

3. Paerl, H. W.; Rossignol, K. L.; Hall, N. S.; Peierls, B. L.; Wetz, M. S. Phytoplankton community indicators of short- and long-term ecological change in the anthropogenically and climatically impacted Neuse River Estuary, North Carolina, USA. Estuaries Coasts 2010, 33: 485-497.

4. Deamer, N. Neuse River Basinwide Water Quality Plan. North Carolina Department of Environment and Natural Resources - Division of Water Quality, 2009.

5. Lebo, M. E., H. W. Paerl, and B. L. Peierls. (2012). Evaluation of progress in achieving TMDL mandated nitrogen reductions in the Neuse River Basin, North Carolina. Environ. Manage. 49: 253-266.

6. http://lnba.net/monitoring; accessed 12/31/2015

7. Murphy, K. R.; Stedmon, C. A.; Graeber, D.; Bro, R. Fluorescence spectroscopy and multiway techniques. PARAFAC. Anal. Methods. 2013, 5(23), 6557-6566.

8. Ohno, T.; Bro, R. Dissolved organic matter characterization using multiway spectral decomposition of fluorescence landscapes. Soil Sci. Soc. Am. J. 2006, 70(6), 2028-2037.

9. http://portal.ncdenr.org/web/wq/ess/bau/refs; accessed 7/29/15

10. Voli, M. T.; Wegmann, K. W.; Bohnenstiehl, D. R.; Leithold, E.; Osburn, C. L.; Polyakov, V. (2013). Fingerprinting the sources of suspended sediment delivery to a large municipal drinking water reservoir: Falls Lake, Neuse River, North Carolina, USA. J. Soils Sediments. 2013, 13 (10), 1692-1707.

11. Stedmon, C. A.; Bro, R. Characterizing dissolved organic matter fluorescence with parallel factor analysis: a tutorial. Limnol. Oceanogr.: Methods 2008, 6 (11), 572-579.

12. Helsel, D. R.; Hirsch, R. M., Eds. Statistical methods in Water Resources. In Studies in Environmental Science (Vol. 49), Elsevier, New York, 1992.

13. Graeber, D.; Gelbrecht, J.; Kronvang, B.; Gücker, B.; Pusch, M. T.; Zwirnmann, E. Technical Note: Comparison between a direct and the standard, indirect method for dissolved organic nitrogen determination in freshwater environments with high dissolved inorganic nitrogen concentrations. Biogeosciences. 2012, 9 (11), 4873-4884.

14. Lee W.T. \& Westerhoff P. Dissolved organic nitrogen measurement using dialysis pretreatment. Environ. Sci. Technol. 2005, 39, 879-884.

15. https://engineering.purdue.edu/mapserve/LOADEST/ 